\title{
Seasonal and interannual behaviour of groundwater catchment boundaries in a Chalk aquifer
}

\author{
S.J. Parker ${ }^{1}$, A.P. Butler ${ }^{1}$, C.R. Jackson ${ }^{2}$ \\ ${ }^{1}$ Imperial College, London \\ ${ }^{2}$ British Geological Survey, Keyworth
}

\begin{abstract}
Groundwater catchment boundaries and their associated groundwater catchment areas are typically assumed to be fixed on a seasonal basis. We investigated whether this was true for a highly permeable carbonate aquifer in England, the Berkshire and Marlborough Downs Chalk aquifer, using both borehole hydrograph data and a physics-based distributed regional groundwater model. Borehole hydrograph data time series were used to construct a monthly interpolated water table surface, from which was then derived a monthly groundwater catchment boundary. Results from field data showed that the mean annual variation in groundwater catchment area was about $20 \%$ of the mean groundwater catchment area, but interannual variation can be very large, with the largest estimated catchment size being approximately $80 \%$ greater than the smallest. The flow in the river was also dependent on the groundwater catchment area. Model results corroborated those based on field data. These findings have significant implications for issues such as definition of source protection zones, recharge estimates based on water balance calculations and integrated conceptual modelling of surface water and groundwater systems.
\end{abstract}

\section{Introduction}

The concept of the groundwater catchment is routinely used for a number of purposes in groundwater hydrology. For quantification of water resources, the groundwater catchment can be used as part of the water budget calculation to estimate a recharge flux. For protection of water quality, groundwater source protection zones are used in a number of countries to protect drinking water abstractions (e.g. US EPA, 1993), and it is common to include the whole aquifer as one of a group of zones around the abstraction point, as in the UK, for example, with source catchment protection zones (Environment Agency, 2013). For conceptual hydrological models, which include a groundwater component, it is necessary to specify a groundwater catchment area to calculate the aggregated recharge component to groundwater.

Groundwater catchments tend to be assumed to be fixed in time. As a motivation for joining groundwater models of neighbouring catchments, Black et al. (2012) state that groundwater divides are often assumed to be static, yet suggest that they may vary seasonally. Similarly, Wheater et al. (2007) discuss the seasonal behaviour of parts of a Chalk aquifer. They indicate that the groundwater divide varies seasonally, but do not attempt to characterize the extent of the movement. Referring to another carbonate aquifer, the Upper Floridan limestone aquifer, Grubbs and Crandall (2007) refer to the migration of one section of the lateral groundwater flow boundary of the order of tens of kilometres as a result of groundwater withdrawals over the past century. Sophocleous (1991) describes the strong hydraulic connections that arise as a result of highly transmissive buried channels between sites located approximately $80 \mathrm{~km}$ apart. Despite this awareness of long-range connections in permeable subsurface systems and the capacity of groundwater divides to shift, there are, to the authors' knowledge, no reports of the time-variant behaviour, both seasonal and interannual, of groundwater catchment areas. Although these types of groundwater catchments are acknowledged to vary seasonally in their extent (e.g. Wheater et al., 2007), for modelling purposes, the groundwater catchment area is assumed to be constant in both conceptual groundwater models such as INCA (e.g. Wade et al., 2002), CATCHMOD (e.g. Wilby et al., 1994) and IHACRES_GW (e.g. Ivkovic et al., 2009) and also in some distributed groundwater models (e.g. Grapes et al. (2006) and Clausen et al. (1994)). 
This paper considers the time-variant behaviour of those groundwater catchments which are highly permeable and cover relatively large areas. Such catchments have relatively little surface drainage, but groundwater systems which may be interdependent over large distances. We focus on a Chalk catchment, the River Lambourn in central southern England. Using observation borehole time series data, we interpolate the water table surface, from which we identify the time-variant groundwater catchment area. We then use an existing regional groundwater model to construct time series of the groundwater catchment area for the river, in order to ascertain whether the pattern of behaviour inferred from interpolated field data can be reproduced by the model; because model output is based on a regular grid, this eliminates the uncertainty associated with the interpolation mechanism. The model is used to assess interpolation performance by comparing the groundwater catchment area derived from entire model output with groundwater catchment area based only on model output from those model nodes that correspond to observation borehole locations.

\section{Study Area}

The River Lambourn is a predominantly groundwater-fed river, with a baseflow index of 0.96 (Marsh and Hannaford, 2007), situated in the Chalk of the Berkshire Downs in the southern UK (Figure 1). The principal streamflow gauging station for the surface water catchment is located at Shaw, where the river then joins the River Kennet, a major tributary of the River Thames. A map of the geology is shown in Figure 2. The region forms the north-western part of the London Basin syncline. For the region enclosed by the dashed line in Figure 1, to the west of the River Thames, average elevations are between $150 \mathrm{~m}$ asl in the east and $200 \mathrm{~m}$ asl in the west (Whitehead et al., 2002), where the landscape is characterized by permanent chalk grassland and arable farming (Environment Agency, 2004). For the same region, east of the River Thames, the chalk hills are known for their woodland cover, particularly beech. The north-facing escarpment on the northernmost edge of the region is associated with the development of a line of springs between the base of the Chalk and the Upper Greensand below. In addition to the unconfined Chalk, the principal aquifer for the area, the Upper Greensand acts as a minor aquifer. The dip of the geology on the northern part of the syncline is up to two degrees towards the south and southeast, with the result that the Chalk disappears below younger deposits of Palaeogene age at lower topographical elevations. Long-term average rainfall varies between $580 \mathrm{~mm}$ per annum in the lower areas of the region and $810 \mathrm{~mm}$ per annum over the higher ground and is approximately uniformly distributed throughout the year (Jackson et al., 2011). Annual potential evapotranspiration (PET) is around $600 \mathrm{~mm}$ per annum but varies seasonally.

Chalk is a dual permeability, dual porosity medium, with a fine-grained, high porosity, lowpermeability matrix and a fracture network that enables the transfer of water (Price et al., 1993). Typically, fracture porosity is of the order of $1 \%$. One consequence of this is that seasonal fluctuation in water table elevation can be substantial. A rise in the water table of between 10 and $20 \mathrm{~m}$ is common across interfluve areas at the beginning of the winter recharge season as shown for two boreholes (Figure 3), the locations of which are shown in Figure 4. Figure 3 shows that not only is there a seasonal variation in water table elevation but also that variation between years can be significant. For example, the very high water table elevation seen in early 1990 contrasts with the drought conditions of early 1992. This volatility in water table elevation has the consequence that Chalk river systems are often characterized by bourne behaviour, whereby the location of the source of the river moves up and down the river valley on a seasonal basis. In the case of the River Lambourn, this can vary by up to $10 \mathrm{~km}$ between wet and dry periods. 


\section{Regional model}

The regional model used is described by Jackson et al. (2011). The model was implemented using the finite difference code ZOOMQ3D, which allows for mesh refinement in areas of interest. The model therefore has a general mesh spacing of $2 \mathrm{~km}$, with refinement to $500 \mathrm{~m}$ in the area around the rivers Lambourn and Pang. The model is divided into three layers, partly because Chalk aquifer characteristics vary markedly with depth (Owen and Robinson, 1978; Williams et al., 2006). With some exceptions (e.g. Foster and Milton, 1974), hydraulic conductivity decreases with increasing depth below the surface. A depth-dependent relationship also exists for storativity. Additionally, aquifer characteristics vary according to lateral position. Thus, transmissivity, and therefore hydraulic conductivity, and storativity are assigned on a zonal basis, with zones broadly representing hydrogeological features. The model was divided into 21 zones for transmissivity and 12 zones for storage. For transmissivity, river valley and dry valley zones were generally assigned higher transmissivities than interfluve zones. For valleys, downstream transmissivity was considered to be higher than upstream transmissivity as the rivers are larger. For interfluves, zones closer to the ChalkPalaeogene boundary were considered to have higher transmissivity than interfluves elsewhere as a result of greater karst development. For storage, a similar relationship is defined, where storage in the river valleys is higher than that in the interfluves, as suggested by Owen and Robinson (1978). Additionally, for the river valleys, where there are known to be alluvial gravels, storage is assigned a higher value because of the high specific yield of the gravels. The regional model therefore attempts to replicate the known hydrogeological features of Chalk catchments. Recharge input is modelled using ZOODRM (Mansour and Hughes, 2004) using a Penman-Grindley soil-moisture balance approach (Penman, 1948; Grindley, 1967). This gave a mean modelled recharge for the Lambourn catchment of $277 \mathrm{~mm}$ per annum, close to the value of $280 \mathrm{~mm}$ per annum specified by Brettell (1971).

\section{Methodology}

\section{Spatial interpolation}

For spatial interpolation of groundwater levels, the interpolation scheme of choice tends to be kriging (e.g. Aboufirassi and Mariño, 1983; Gundogdu and Guney, 2007; Kumar, 2007; Rivest et al., 2008). Implementation of the kriging algorithm, however, is not trivial, as it requires the identification and removal of the spatial trend in the data, the choice of a theoretical variogram and the explicit treatment of anisotropy, where that is considered significant. For the case presented here, there is a marked change in water table slope associated with the scarp slope (Figure 5); in order to implement a kriging algorithm that identifies the position of the groundwater divide, it is necessary to identify that point at which the anisotropy changes. However, in order to identify that point at which the anisotropy changes, it is necessary to implement a kriging algorithm.

In this study, we used thin plate splines (TPS) as an interpolator for the groundwater surface. An advantage of TPS is that there is no need to specify the nature of the spatial structure in advance (Hutchinson, 1995). One criticism of TPS is that they may produce a view of reality which is unrealistically smooth (Hengl, 2009). However, this is not thought to be a serious objection in the case of Chalk groundwater systems, as the highly permeable nature of these catchments and the relatively low degree of heterogeneity at the meso-scale $(\mathrm{km})$ result in a phreatic surface that is relatively smooth. Although there are many examples in the literature of the implementation of TPS for climate variables (e.g. Hancock and Hutchinson (2006) and references therein), there seem to be few examples of the implementation of TPS for the interpolation of the water table surface. However, Lin and Anderson (2003 and references therein) report a test case in which TPS was found to be superior to the use of kriging in the interpolation of the water table surface and suggest that this interpolator is efficient for a continuous smooth surface. The TPS algorithm was implemented using the function Tps() from the R library 'fields' (Furrer et al., 2012; R Core Team, 2013), using splines of both degrees 2 and 3. 


\section{Control points}

Borehole locations used as control points for the interpolation are shown in Figure 4, together with locations of river nodes used. On the basis that the variations in the groundwater levels in the aquifer are much larger than the variations in river stage, river nodes were assigned a constant head value equal to $1 \mathrm{~m}$ above the elevation of the river bed. The choice of $1 \mathrm{~m}$ was made so that groundwater catchment area based on interpolation of field data was consistent with the groundwater catchment area based on complete model output; based on the rivers themselves, the model was constructed with a river stage approximated as a constant $1 \mathrm{~m}$ above the river bed. The spring boundary condition, however, poses a particular problem as there are a large number of springs located on the scarp slope of the catchment. This means a choice has to be made as to which springs along with their associated elevations are used as boundary conditions for interpolation. Along scarp slope valleys, where the water table intersects the surface, springs typically occur at three elevations, namely, lower, upper and highest. For example, at Easting $428000 \mathrm{~m}$ (Figure 4), there are three springs (marked as solid triangles) at elevations 90,96 and $110 \mathrm{~m}$ asl. For the purposes of interpolation, elevations of the highest springs, after initial inclusion, were eventually disregarded, as discussed in the results. A table of the spring elevations used, together with their locations, is shown in Table I.

For the interpolation of field data, three distinct sets of spring boundary conditions were used, a set of springs at lower elevations (column three, Table I, referred to as set 1 ) and a set of springs at higher elevations (column four, Table I, referred to as set 2). For sets 1 and 2, there are two particular limitations. Firstly, what is required as a boundary condition for interpolation is the potentiometric head, but what is used is the elevation of the spring as a proxy for this. Thus, when the spring is active, for example, the head will exceed the elevation. Secondly, in reality, springs may be switched on and off with the rise and fall of the water table, but for interpolation purposes, potentiometric head values for springs are set as constants. To mitigate these problems, therefore, a variable head spring condition (set 3) was implemented at each location shown in Table I, in the following manner. The time series of head values at a nearby borehole, Kingston Hill Barn, was normalized to a time series varying between zero and one. The resultant time series was then applied to each spring location shown in Table I to give a time series of head values, for each spring location, varying between the lower and higher elevations at that spring location. Therefore, the interpolation was implemented in six ways, using three sets of spring conditions, with each set implemented using both second and third degree splines.

For each month, it is possible to produce interpolated, gridded output, which can then be used to delineate the groundwater catchment. The destination grid for interpolated field data was set to be identical to the regional groundwater model grid. In order to determine the catchment area, a catchment outlet point has to be defined. This is problematic, especially given the permeable nature of the catchment, as the assignment of a single fixed outlet point can result in a volatile designation of the catchment area, because the groundwater surface is mobile. To counteract this problem, the groundwater catchment area was defined using multiple outlet points as shown in Figure 4. For each outlet point, the contributing nodes were ascertained using a single direction flow algorithm that is implemented in the subcatch() function from the R library 'topmodel' (Buytaert, 2011; R Core Team, 2013). The catchment delineation was then ascertained by amalgamating any nodes that acted as contributing nodes to any outlet point at each time step, but avoiding double counting of contributing nodes. In other words, for any given point in time, a contributing area is calculated for each outlet point river node shown in Figure 4, and all the resulting areas are then superimposed upon one another to give a single, aggregated contributing area at that point in time. This enables the generation of a time series of the groundwater catchment area by month and year.

In order to address the uncertainties arising from the choice of boundary conditions and from the use of any interpolation scheme where there is spatially sparse data, the behaviour of the groundwater catchment area was investigated using a distributed physics-based groundwater model. The model has two principal advantages over results based on interpolation of field data. Firstly, because head 
output is produced at every model node at every time step, the water table surface, as generated by the model, can be defined unequivocally, with the only constraints being the model grid resolution and the model time step. Secondly, boundary conditions, in relation to groundwater catchment delineation, do not apply as, for example, springs are switched on and off as part of the model definition. That is, spring behaviour is determined endogenously. An additional use of the model is that, by sampling head output from model nodes whose locations correspond to the locations of boreholes shown in Figure 4, model output can then be interpolated in the same way as field data, which enables the comparison between groundwater catchment area obtained from entire model output with groundwater catchment area based on a sample of model output. This enables an assessment of the interpolation scheme.

\section{Time series coverage and comparison with baseflow}

Analysis was carried out for the period May 1975 to October 2002. Time series of groundwater catchment areas were compared with corresponding time series of baseflow. Baseflow for the River Lambourn was calculated using the IHLowFlow method (Gustard et al., 1992).

\section{Results}

\section{Interpolation of Field Data}

Using the aforementioned interpolation scheme applied to the borehole data with springs' set 1 and TPS degree 3, two contour maps of groundwater heads are shown in Figure 6 to demonstrate typical examples of seasonal high water table (March 1994) and seasonal low water table (September 1994). Both maps appear to be reasonable with a steep hydraulic gradient on the escarpment, a Vshaped nesting of contours moving up the river valley and water table plateaus over higher ground.

Figure 7 shows results of the interpolated groundwater catchment area based on field data using TPS for low spring boundary conditions. Clearly evident is the variability in the catchment area with typical annual variations of between 20 and $40 \mathrm{~km} 2$ and minimum and maximum areas for the period 19752002 of 91 and $175 \mathrm{~km} 2$ using a TPS of degree 2 and 103 and $186 \mathrm{~km} 2$ using a TPS of degree 3, respectively. Also evident are the prolonged reduced catchment areas in 1976, 1992 and 1997, where the area did not vary according to its normal annual cycle. Mean catchment areas are 137 and $153 \mathrm{~km} 2$ for splines of degrees 2 and 3, respectively, for low spring conditions, and the mean seasonal difference was $32 \mathrm{~km} 2$ for the latter configuration, that is $20 \%$ of the mean catchment area.

Figure 8 shows the distributions of groundwater catchment areas, comparing the effects of different spring boundary conditions and spline implementations. The figure suggests that the area is strongly controlled by the degree of spline, and that third degree spline gives a higher mean catchment area, although this may not be a general result. Figure 9 shows the relationship between the catchment area and baseflow. Mean baseflow at the Shaw gauging station was calculated as 146.4 megalitres per day, giving a baseflow index of 0.97 for the period May 1975 to October 2002. Each point in Figure 9 represents a single month in the analysis period and shows the groundwater catchment area and its associated baseflow. It can be seen that higher baseflows are associated with larger catchment areas, and also, that there is an upper limit to catchment area; at low flows, increases in flow are associated with increases in catchment size, but at higher flows, the catchment size remains relatively constant. Also shown is the formation of a hysteresis loop, in that flows in the early summer (late April/May) are similar to those in the early winter (December), but with catchment areas significantly larger in the early summer.

\section{Groundwater model simulations.}

Figure 10 shows a comparison of the results of the six combinations of spring boundary conditions and degree of spline used in the interpolation. Additionally, the figure shows the distribution of catchment areas based on complete model output. As with the interpolation of field data, the figure suggests 
that the groundwater catchment area is strongly controlled by the degree of spline used, that the third degree spline results in both a higher mean catchment area than the second degree spline and a better estimate of the catchment area derived from complete model output. With regard to spring boundary conditions, there is little difference between an interpolation implementation that uses fixed lower springs (set 1) compared with the one that uses a normalized, time-variant spring boundary condition (set 3). However, the time-invariant spring boundary condition with springs at higher elevations (set 2) not only results in an overestimation of catchment area but also results in a reduction in the typical range of catchment areas generated. This is the reason why springs at highest elevations were disregarded in the interpolation of field data, because even the use of time-invariant mid-elevation springs gave a poor fit when compared with the complete model output. A time series of the groundwater catchment area comparing complete model output and interpolated model output is shown in Figure 11. It can be seen that the large seasonal variation suggested by the interpolation of field data is also evident in the model, although the mean annual variation in the model area (using complete model output) was considerably larger at $34 \%$ of the mean annual catchment area. Additionally, there are instances where the seasonal variability is atypical, for example, the winters of 1992 and 1997. Figure 12 supports the implications drawn from Figure 9, suggesting a clear relationship between the flow and catchment area and also hysteresis within that relationship. For example, it can be seen that modelled baseflows for January and May 1995 are similar in magnitude (161 and 163 megalitres per day, respectively), but associated catchment areas differ significantly (126 compared with $163 \mathrm{~km}^{2}$, respectively).

\section{Discussion}

In this paper, we considered a Chalk catchment, the River Lambourn, which is both highly groundwater dominated, with a baseflow index of more than $90 \%$, and which forms part of a larger hydrogeological framework. We posed the question to what extent the groundwater catchment area for such a river, where groundwater catchment area is defined by the topography of the water table surface, can be considered constant. We used field observations of potentiometric head to construct an interpolated surface of the water table through the use of TPS. Using a physics-based finite difference groundwater model, whose domain includes this particular catchment, we then used the output from that model to delineate the groundwater catchment as defined by the model. Then, using model output from the set of model nodes whose locations coincided with observation borehole locations in the field, we interpolated model output in order to assess the uncertainty introduced by the interpolation. The objectives of this paper were to investigate the time-variant behaviour of catchment areas for groundwater-dominated catchments. The borehole data from field observations indicate that the groundwater catchment areas vary, both seasonally and interannually. On a seasonal basis, the catchment area typically varied by between 20 and $40 \mathrm{~km} 2$ with minimum and maximum areas between 1975 and 2002 of 103 and $186 \mathrm{~km} 2$ using a TPS of degree 3 and mean catchment areas of $153 \mathrm{~km} 2$ (low spring boundary condition) and $160 \mathrm{~km} 2$ (normalized spring boundary condition). A physics-based model was used to ascertain whether the catchment behaviour indicated by the field data was reasonable. The model has three advantages over the analysis using field data. Firstly, there is no interpolation error for the model. That is, the groundwater catchment area can be defined using gridded output which is complete. Secondly, with regard to the delineation of groundwater catchment, there is no issue concerning boundary conditions, particularly spring heads, as these are determined endogenously within the model. Thirdly, there is no issue with irregular time series; the analysis using field data uses baseflow data at the principal gauging station and head values taken from a sample of boreholes. However, the timings of borehole readings and gauge readings frequently do not coincide, and therefore, for the comparison between river flow and groundwater catchment area, some temporal adjustment has to be made.

The model enabled an assessment of the use of TPS as an interpolator by comparing the groundwater catchment area derived from complete model output with that derived from the interpolation of 
potentiometric heads from a limited sample of model nodes. A comparison was made using different spring boundary conditions and different spline implementations. Three sets of spring boundary conditions, each used in conjunction with splines of degrees 2 and 3, showed that the interpolated area using the second degree splines underestimated that derived from the complete model output. Using the third degree splines, however, a time-invariant spring boundary head using the elevations of low springs as a proxy for potentiometric head and a time-variant spring boundary head conditioned according to the behaviour of a nearby borehole both reproduced very well the area computed using all model nodes. Model results also showed the catchment area to be very dynamic with a mean annual variation in the model area of $34 \%$ of the mean annual catchment area.

This variability in catchment area has implications for conceptual models. Conceptual models such as INCA (e.g. Wade et al., 2002), CATCHMOD (e.g. Wilby et al., 1994) and IHACRES_GW (e.g. Ivkovic et al., 2009) treat the catchment as a single homogeneous unit, to which a flux of hydrologically effective rainfall (HER) is applied as a time series to generate a streamflow response. That HER flux is necessarily scaled up by an explicit designation of catchment area, which is time invariant. The analysis presented here, however, strongly suggests that a conceptual model applied to such a strongly groundwaterdominated catchment might need to take account of the fact that the contributing area to the stream varies with time; if not taken into account, then the constraint of a fixed area would require a range of modelled HER values greater than that which would be observed in principle in the field. In other words, one incorrectly configured input (a constant catchment area) would be compensated for by a second incorrectly configured input (an overestimation of the range of possible HER values). Additionally, the analysis presented here demonstrated that the relationship between streamflow and catchment area exhibits hysteresis, so that there is no one-to-one relationship between the two variables.

\section{Conclusions}

This paper sought to investigate the time-variant behaviour of groundwater catchment areas in permeable catchments. In particular, we examined the behaviour of a UK Chalk catchment, whose associated river has a very high baseflow index of $96 \%$. We found that the mean annual variation in groundwater catchment area was about $20 \%$ of the mean groundwater catchment area, but interannual variation can be very large, and the largest estimated catchment size was about $80 \%$ greater than the smallest. This raises questions relating to those groundwater topics set out in the introduction that relate to catchment area, namely, source protection zones, recharge estimates based on water balance calculations and integrated conceptual modelling of surface water and groundwater systems. It would be interesting to see whether the results presented here could be replicated in other permeable groundwater systems, notably other carbonate aquifers and also possibly large gravel aquifers.

\section{Acknowledgements}

This work was undertaken as part of the 'Modelling ground water flood risk in the Chalk aquifer from future extreme rainfall events' project funded by NERC (Grant NE/E002307/1). Jackson publishes with the permission of the Executive Director of the British Geological Survey. 


\section{References}

Aboufirassi M, Mariño MA. 1983. Kriging of water levels in the Souss Aquifer, Morocco. Mathematical Geology 15(4): 537-551.

Black AD, Lewis RT, Grout MW, Witterick WR. 2012. Crossing boundaries, the influence of groundwater model boundaries and a method to join and split MODFLOW models Geological Society, London, Special Publications v.364, 155-172. DOI: 10.1144/SP364.11

Brettell EJ. 1971. Report on the Lambourn valley pilot scheme, 1967- 1969. Thames Conservancy: Reading; 172.

Buytaert W. 2011. Topmodel: implementation of the hydrological model TOPMODEL in R. R package version 0.7.2-2. http://CRAN.R-project.org/package=topmodel

Clausen B, Young AR, Gustard A. 1994. Modelling the impact of groundwater abstractions on low-river flow. FRIEND: flow regimes from international experimental and network data, IAHS Publ. 221, 77-85.

Environment Agency (UK). 2004. The Kennet and Pang catchment abstraction management strategy.

Environment Agency (UK). 2013. Groundwater protection: principles and practice (GP3).

Foster SSD, Milton VA. 1974. The permeability and storage of an unconfined Chalk aquifer. Hydrological Sciences Bulletin 19(4): 485-500.

Furrer R, Nychka D, Sain S. 2012. Fields: tools for spatial data. R package version 6.7. http://CRAN.Rproject.org/package=fields

Grapes TR, Bradley C, Petts GE. 2006. Hydrodynamics of floodplain wetlands in a chalk catchment: the River Lambourn, UK. Journal of Hydrology 320(3-4): 324-341.

Grindley J. 1967. The estimation of soil moisture deficits. Meteorological Magazine 76: 97-108.

Grubbs JW, Crandall CA. 2007. Exchanges of water between the upper floridan aquifer and the lower Suwannee and lower Santa Fe Rivers, Florida. U.S. Geological Survey Professional Paper 1656C, 83.

Gundogdu K, Guney I. 2007. Spatial analysis of groundwater levels using universal kriging. Journal of Earth System Science 116(1):49-55.

Gustard A, Bullock A, Dixon JM. 1992. Low flow estimation in the United Kingdom. Institute of Hydrology Report No. 108. Wallingford, UK.

Hancock PA, Hutchinson MF. 2006. Spatial interpolation of large climate data sets using bivariate thin plate smoothing splines. Environmental Modelling and Software 21: 1684-1694.

Hengl T. 2009. A practical guide to geostatistical mapping office for official publications of the European communities, Luxembourg (ISBN:978-92-79-06904-8).

Hutchinson MF. 1995. Interpolating mean rainfall using thin plate smoothing splines. International Journal of Geographical Information Science 9(4): 385-403.

Ivkovic KM, Letcher RA, Croke BFW. 2009. Use of a simple surface-groundwater interaction model to inform water management. Australian Journal of Earth Sciences 56: 61-70.

Jackson CR, Meister R, Prudhomme C. 2011. Modelling the effects of climate change and its uncertainty on UK Chalk groundwater resources from an ensemble of global climate model projections. Journal of Hydrology 399: 12-28.

Kumar V. 2007. Optimal contour mapping of groundwater levels using universal kriging - a case study. Hydrological Sciences Journal 52(5):1038-1050. 
Lin Y-F, Anderson MP. 2003. A digital procedure for ground water recharge and discharge pattern recognition and rate estimation. Groundwater 41(3): 306-315.

Mansour MM, Hughes AG. 2004. User's manual for the distributed recharge model ZOODRM. British Geological Survey Internal Report, IR 04150.

Marsh TJ, Hannaford J. 2007. The summer 2007 floods in England and Wales - a hydrological appraisal centre for ecology and hydrology, 32. ISBN: 978-0-9557672-4-1

Owen M, Robinson VK. 1978. Characteristics and yield in fissured chalk In: Thames groundwater scheme: proceedings of the conference held at Reading University, 12-13 April, 1978, Institution of Civil Engineers, London, 33-49.

Penman HL. 1948. Natural evaporation from open water, bare soil and grass. Proceedings of the Royal Society of London. Series A: Mathematical and Physical Sciences 193(1032): 120-145.

Price M, Downing RA, Edmunds WM. 1993. The Chalk as an aquifer. In The Hydrogeology of the Chalk of North-West Europe, Downing RA, Price M, Jones GP (eds). Clarendon Press: Oxford.

$\mathrm{R}$ Core Team. 2013. R: a language and environment for statistical computing. $\mathrm{R}$ Foundation for Statistical Computing, Vienna, Austria. URL http://www.R-project.org/.

Rivest M, Marcotte D, Pasquier P. 2008. Hydraulic head field estimation using kriging with an external drift: a way to consider conceptual model information. Journal of Hydrology 361: 349-361.

Sophocleous MA. 1991. Stream-floodwave propagation through the Great Bend alluvial aquifer, Kansas: field measurements and numerical simulations. Journal of Hydrology 124: 207-228.

US EPA. 1993. Guidelines for delineation of wellhead protection areas EPA 440/5-93-001.

Wade AJ, Durand P, Beaujouan V, Wessel WW, Raat KJ, Whitehead PG, Butterfield D, Rankinen K, Lepisto L. 2002. A nitrogen model for European catchments: INCA, a new model structure and equations. Hydrology and Earth System Sciences 6: 559-582.

Wheater HS, Peach D, Binley A. 2007. Characterising groundwater-dominated lowland catchments: the UK Lowland Catchment Research Programme (LOCAR). Hydrology and Earth System Sciences 11: 108-124.

Whitehead PG, Johnes PJ, Butterfield D. 2002. Steady state and dynamic modeling of nitrogen in the River Kennet: impacts of land use change since the 1930s. Science of the Total Environment 282-283: 417-435.

Wilby R, Greenfield B, Glenny C. 1994. A coupled synoptic-hydrological model for climate change impact assessment. Journal of Hydrology 153 (1): 265-290.

Williams A, Bloomfield J, Griffiths K, Butler A. 2006. Characterising the vertical variations in aquifer properties within the Chalk aquifer. Journal of Hydrology 330: 53-62. 
Tables

Table I. Spring boundary conditions

\begin{tabular}{cccc}
\hline Easting $(\mathrm{m})$ & Nothing $(\mathrm{m})$ & $\begin{array}{c}\text { Lower spring } \\
\text { elevation }(\mathrm{m})\end{array}$ & $\begin{array}{c}\text { Upper spring } \\
\text { elevation }(\mathrm{m})\end{array}$ \\
\hline 422,500 & 184,000 & 103.8 & 103.8 \\
420,000 & 182,000 & 111 & 111 \\
423,500 & 184,000 & 108.6 & 116.9 \\
426,000 & 185,500 & 105.3 & 109.3 \\
428,000 & 187,500 & 90.4 & 95.7 \\
429,500 & 188,000 & 95.5 & 108 \\
430,500 & 187,500 & 95.2 & 106 \\
431,500 & 187,500 & 96.25 & 125.5 \\
\hline
\end{tabular}




\section{Figures}

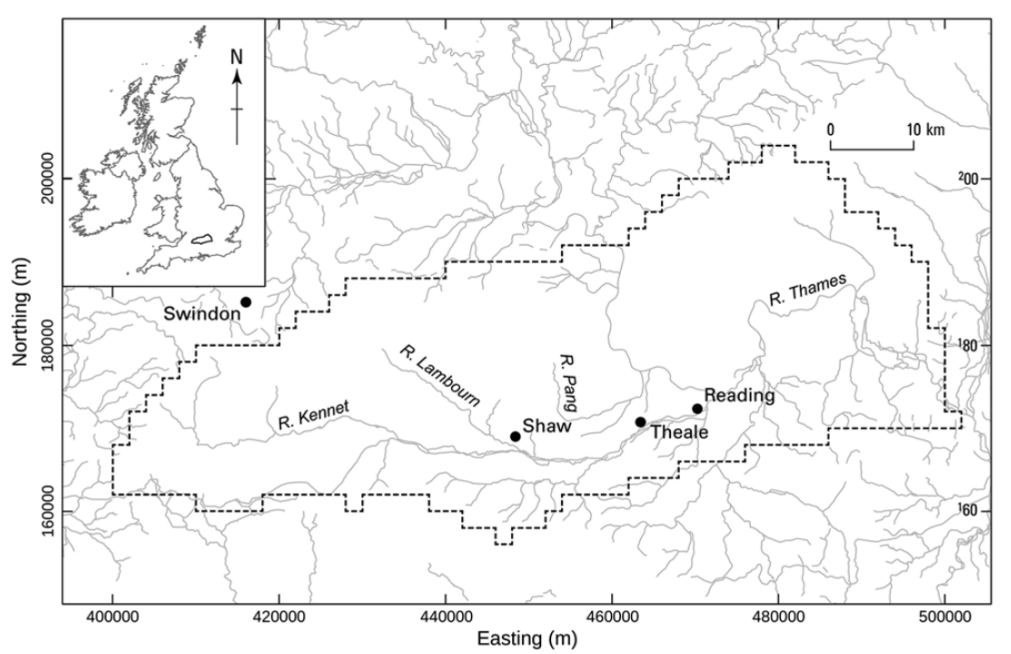

Figure 1. Site location and boundary of regional groundwater model (dashed line)

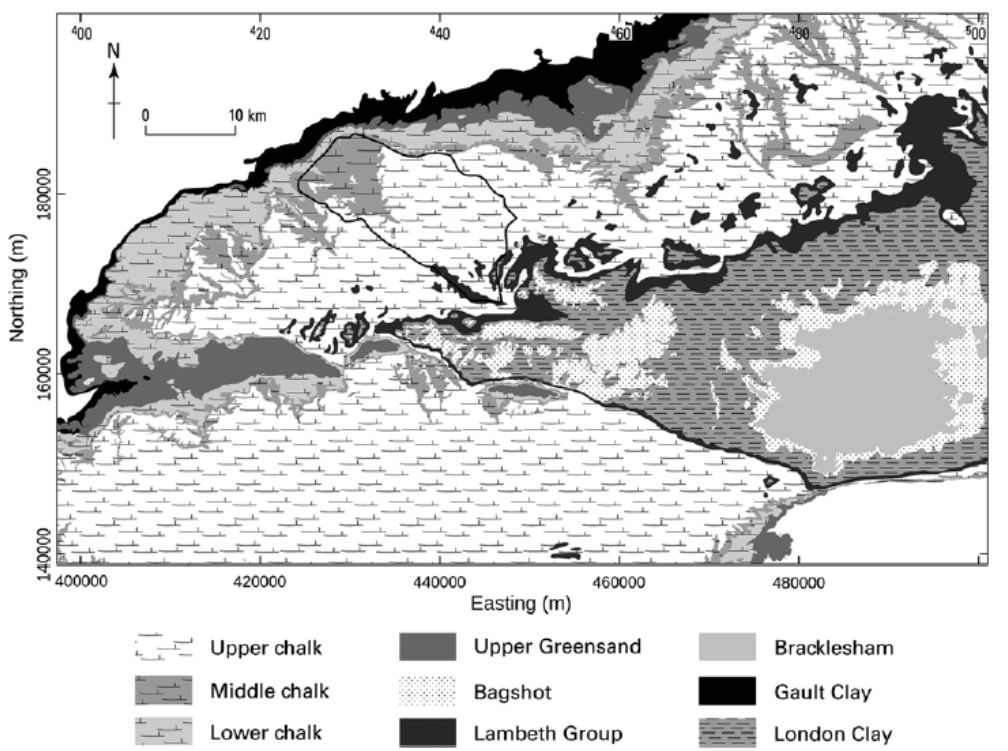

Figure 2. Solid geology of Marlborough and Berkshire downs and Thames basin. Solid line denotes topographic catchment of River Lambourn. (source: British Geological Survey) 


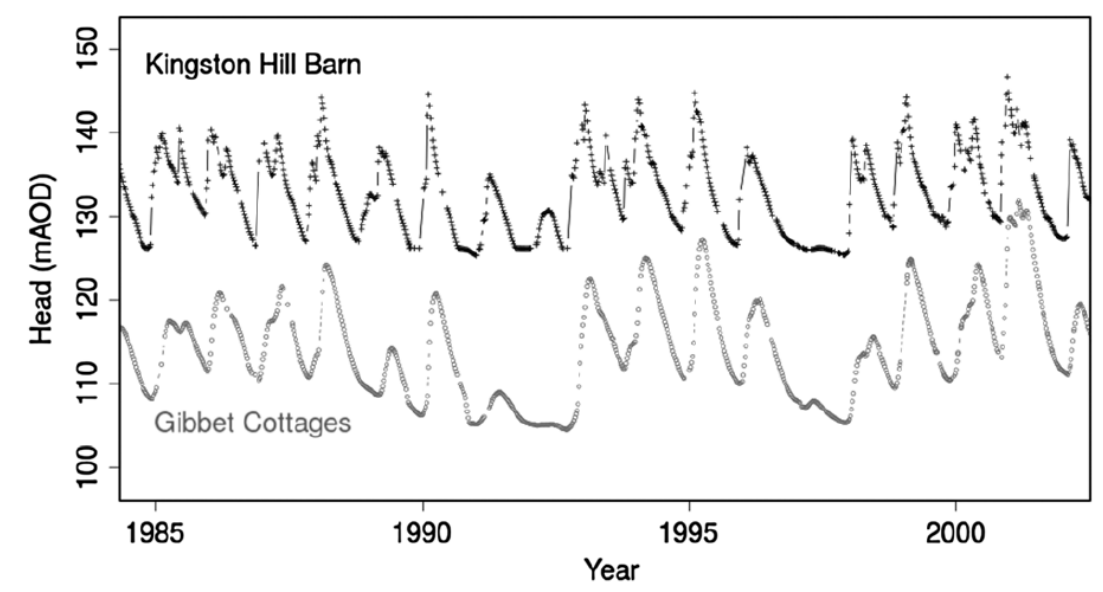

Figure 3. Observed borehole hydrographs demonstrating the marked annual rise in the water table during the winter recharge season. Locations are shown in Figure 4.

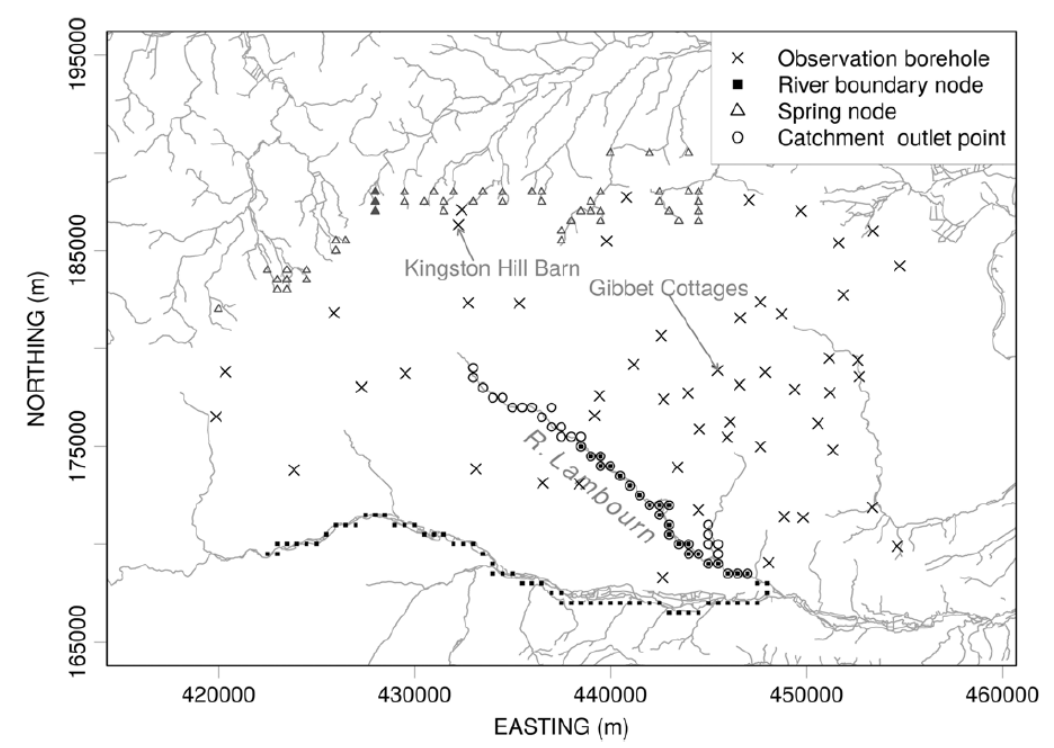

Figure 4. Locations of boreholes and river points at which boundary conditions were specified. River locations are points at which there is perennial flow. Locations of springs are also shown (solid triangles are springs explicitly referred to in text), but only a selection of these was used as boundary conditions, as discussed in the text. Also shown are the catchment outlet points used for delineation of groundwater catchment

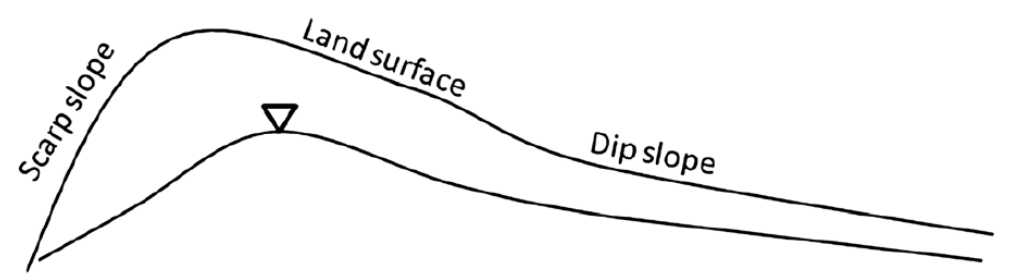

Figure 5. Schematic diagram illustrating the anisotropic nature of the water table slope on either sides of the groundwater divide in relation to scarp and dip slope 

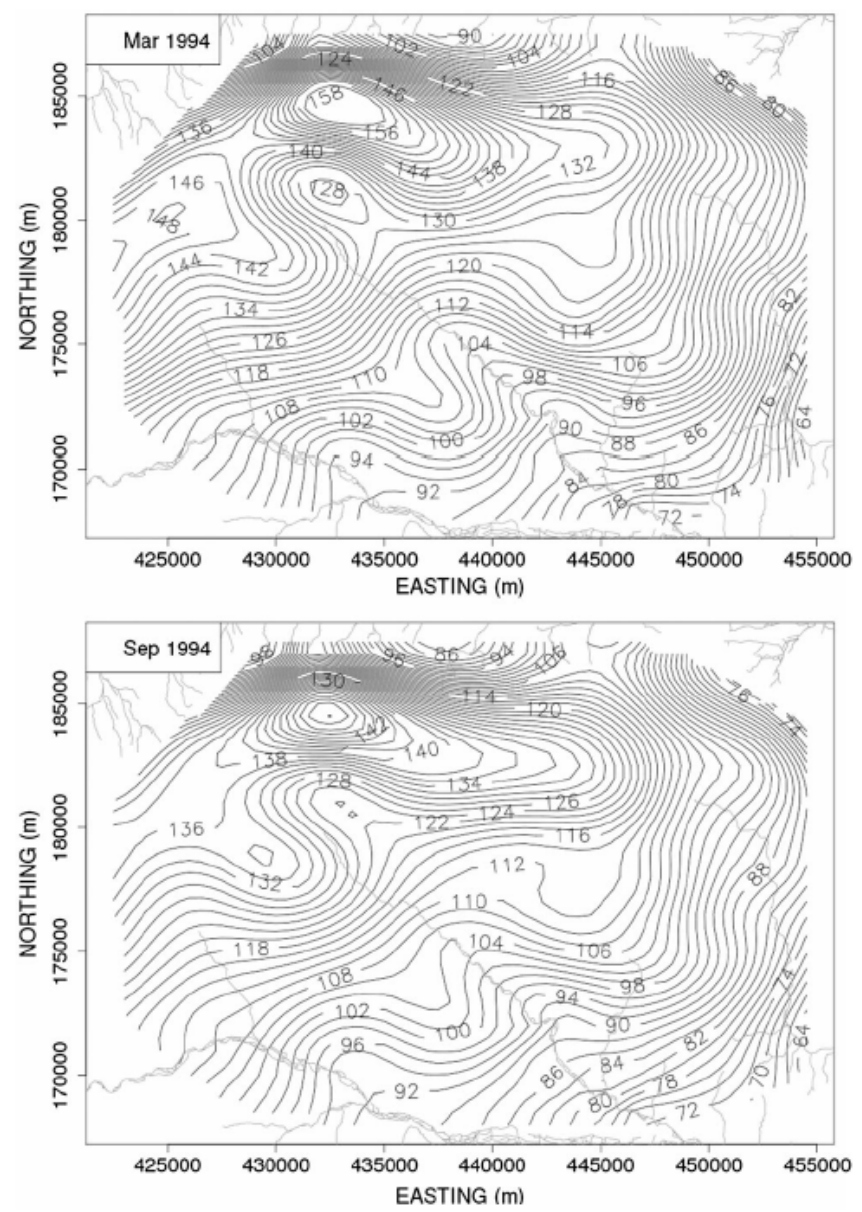

Figure 6. Map of potentiometric surface for the River Lambourn region at seasonal high water table (March) and seasonal low water table (September) using thin plate spline interpolation (degree 3) of field observations. Contoured values are potentiometric head ( $\mathrm{m}$ asl) shown at 2-m interval

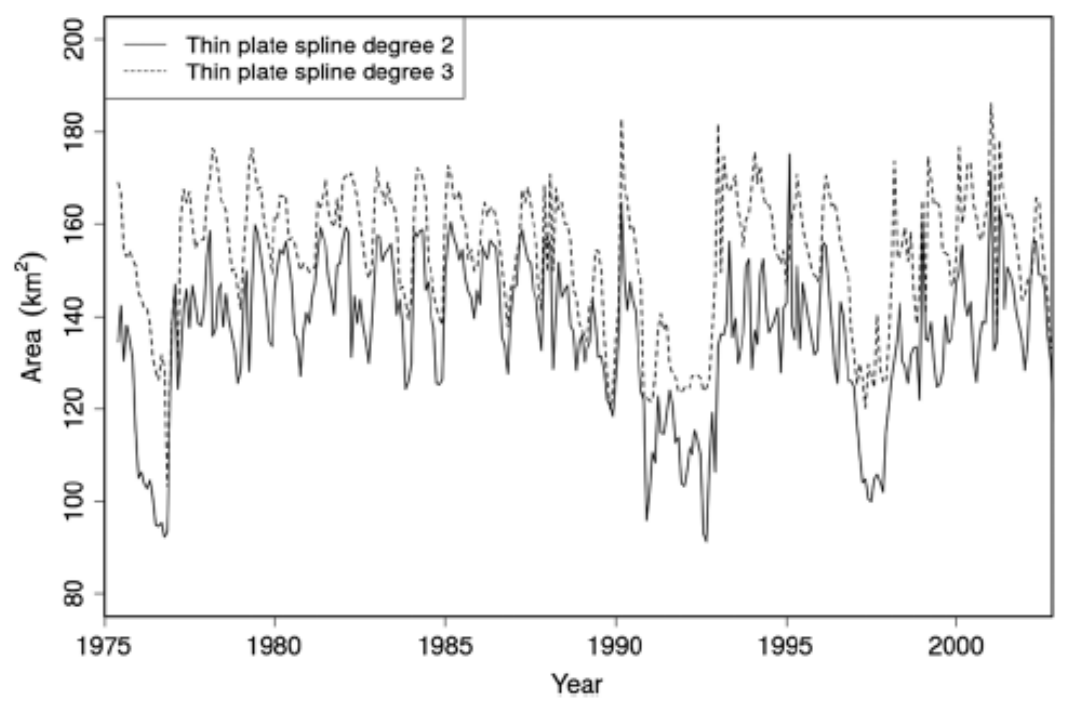

Figure 7. Time series of catchment areas based on interpolation of field data with low spring boundary conditions 


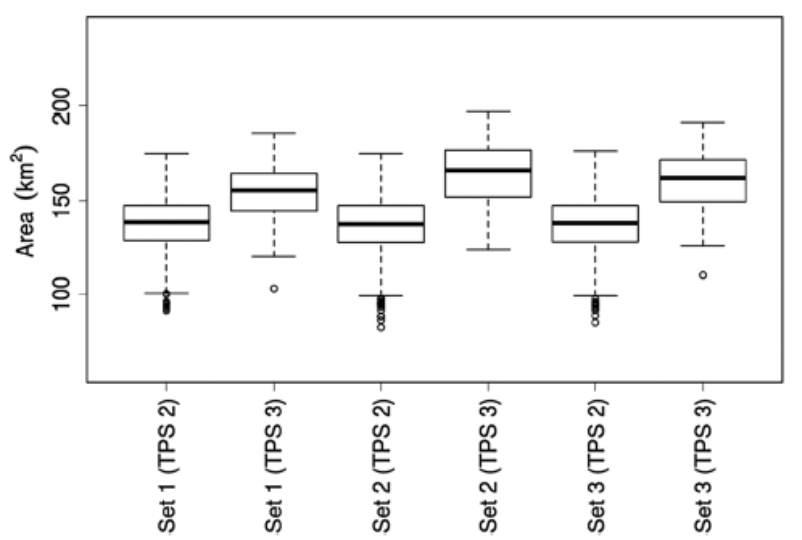

Figure 8. A comparison of the distributions of groundwater catchment areas derived from differing spring conditions and interpolation implementations

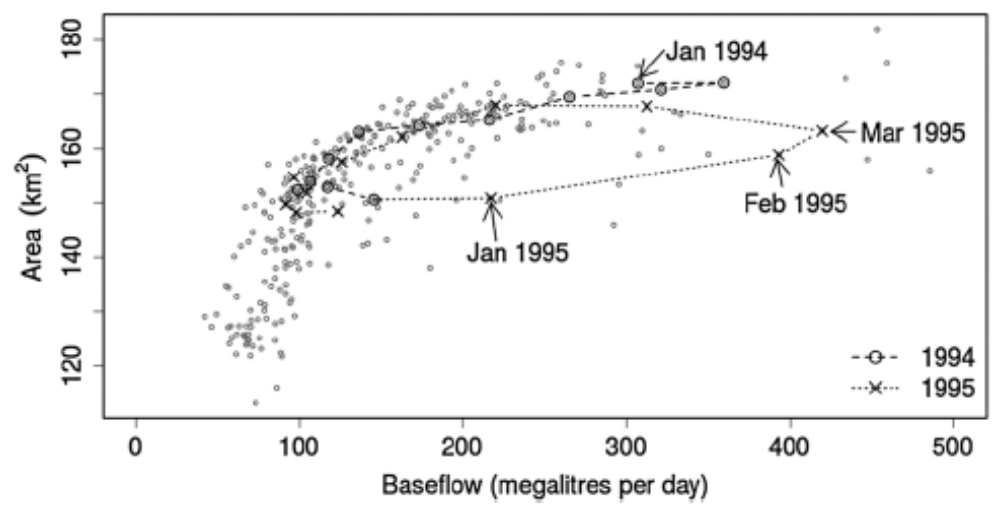

Figure 9. Relationship between baseflow at the Shaw gauging station and groundwater catchment area. Baseflows are derived from observed discharges, and groundwater catchment area is calculated from interpolated field data (TPS degree 3) with low spring boundary conditions. Also shown is the hysteresis in the relationship between baseflow at the Shaw gauging station and groundwater catchment area for the years 1994 and 1995

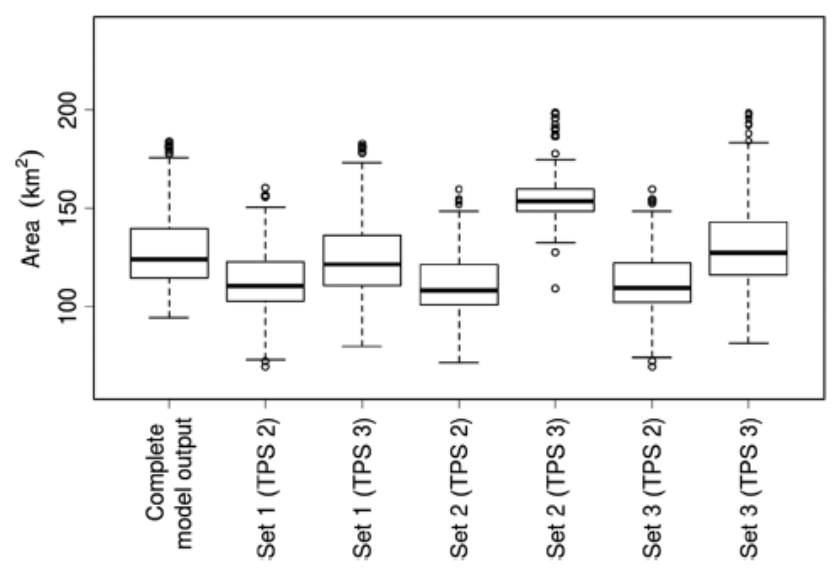

Figure 10. A comparison of the distribution of groundwater catchment between complete model output and area derived from interpolation implementations 


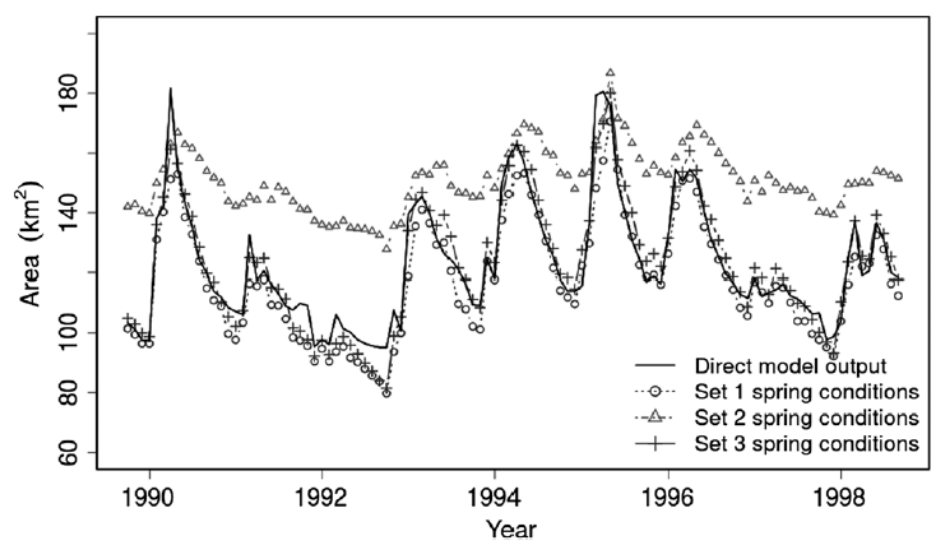

Figure 11. A comparison of time series of groundwater catchment area obtained from direct model output with that obtained from interpolated model output (TPS degree 3) using a sample of model nodes showing influence of spring boundary conditions

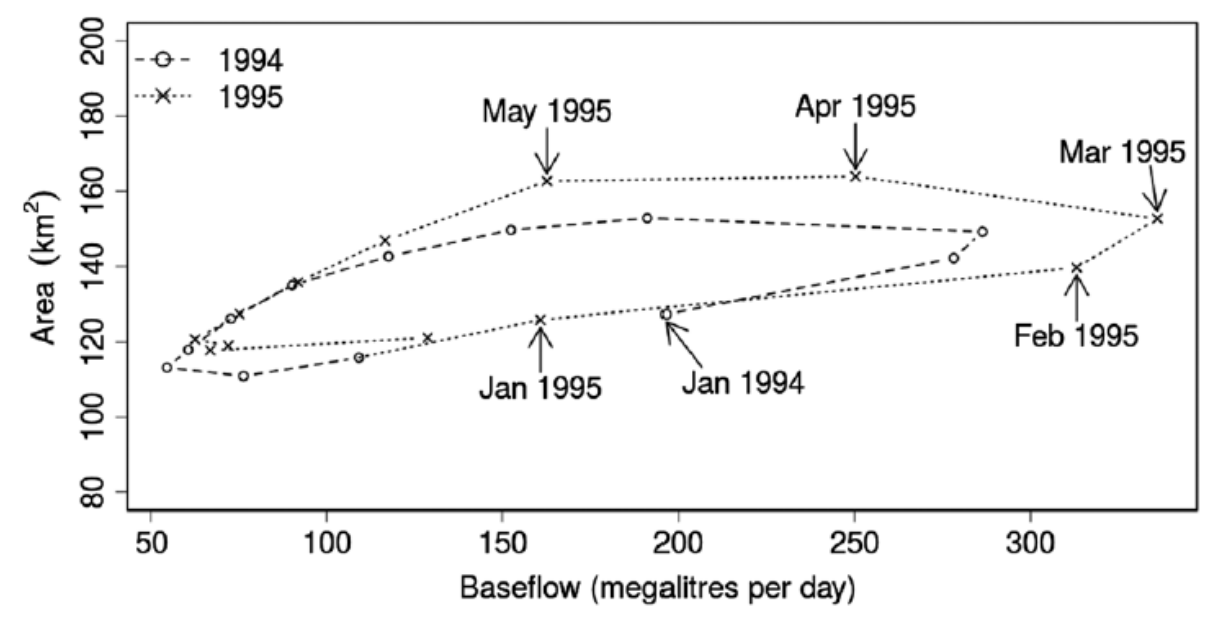

Figure 12. Hysteresis in the relationship between baseflow at principal gauging station and groundwater catchment area for the years 1994 and 1995. Data are modelled monthly baseflow at Shaw and monthly groundwater catchment area derived from complete model output 